\title{
AS MATRONAS DA IGREJA DE ROMA NA ANTIGUIDADE TARDIA
}

\section{THE MATRONS OF THE CHURCH OF ROME IN LATE ANTIQUITY}

\author{
Fabiano de Souza Coelho ${ }^{1}$
}

RESUMO: No presente trabalho iremos apresentar no movimento ascético nos Cristianismos e as relações de gênero existente nessas tendências religiosas na Antiguidade tardia. Demonstrar-se-á as características e as formas de ascese cristã, a renúncia sexual e, por fim, as mulheres na Igreja de Roma em finais do século IV E.C. Essas matronas lideraram um significativo movimento monástico na cidade de Roma, protagonizados pelas mulheres ricas da aristocracia, as viúvas Marcela e Paula, na região de Aventino. Além disso, essas mulheres foram tuteladas pelo monge Jerônimo de Estridão que pode compartilhar a experiência ascética radical do deserto da Síria, o ensino das Letras Sagradas cristãs e línguas orientais.

Palavras-chave: Mulheres. Ascetismo. Renúncia sexual.

ABSTRACT: In the present work we will present in the ascetic movement in Christianity and the gender relations existing in these religious tendencies in Late Antiquity. The characteristics and forms of Christian asceticism, sexual renunciation and, finally, women in the Church of Rome in the late fourth century CE. These matrons led a significant monastic movement in the city of Rome, of the aristocracy, the widows Marcela and Paula, in the region of Aventine. Moreover, these women were tutored by the monk Jerome of Stridon who can share the radical ascetic experience of the Syrian desert, the teaching of Christian Holy letters and Eastern languages.

Key-words: Women. Asceticism. Sexual renunciation.

\section{APRESENTAÇÃO}

Percebemos que os valores construídos em torno do feminino, no decorrer da história da humanidade, foram arquitetados culturalmente pelo masculino para garantir sua dominação social e simbólica. Entendemos que essa condição significa uma articulação que também envolve questões relacionadas à categoria de gênero.

A relação entre mulheres e religiões, tem, através dos tempos, apresentadose como algo ambivalente e paradoxal. Em outros termos, na esfera das religiões, a figura feminina ora foi subjugada ao poder e, por outro lado, exerceu poder (PERROT, 2013, 83).

\footnotetext{
${ }^{1}$ Doutor em História Comparada (PPGHC/IH/UFRJ), orientado pelo Professor Doutor André Leonardo Chevitarese.
} 


\section{HISTÓRIA \\ AS MATRONAS DA IGREJA DE ROMA NA ANTIGUIDADE TARDIA \\ Fabiano de Souza Coelho}

Em representações religiosas sobre a figura feminina, em diversas sociedades, notamos uma espécie de estrutura e organização com distintos significados e valores diferentes, a considerar: protagonistas ou coadjuvantes; aquela que dava a vida ou que semeava morte e doença; honradas ou desonestas; salvadoras ou tentadoras; santas ou pecadoras; anjas ou demônias; ativas ou passivas etc.

Por sua vez, a seita religiosa iniciada por Jesus de Nazaré, no primeiro século da E.C. ${ }^{2}$ na província da Judeia, no Oriente do Império Romano, ajuntou muitos seguidores e, da mesma forma, um número expressivo de seguidoras. Acreditamos que o movimento que Jesus começou na região da Palestina romana é mais bem compreendido como um grupo "sectário", pois esse movimento religioso realizou sete características de uma seita, a conhecer: 1) iniciou com um protesto; 2) repudiou a visão de realidade considerada por evidente pela ordem judaica; 3) estruturou-se como uma comunidade de iguais e sem uma hierarquia organizada; 4) oferecia amizade e aceitação a todos aqueles que se ajuntavam ao grupo, particularmente os marginalizados; 5) foi uma associação voluntária; 6) o movimento de Jesus exigia devotamento integral dos seus seguidores; 7 ) o grupo de Jesus teve suas principais bases e seu principal apoio entre os sofredores e os deserdados (FIORENZA, 1992, 99).

Em torno desse pregador popular judeu, Jesus de Nazaré, tivemos figuras femininas e, com isso, consideramos que obtiveram um papel de suma pertinência nos Cristianismos ${ }^{3}$, pois assumiram inúmeras atividades religiosas no seio daquela comunidade nascente, mesmo em meio a uma estrutura social em que os homens eram representados como protagonistas.

Destarte, mesmo que o grupo de Jesus, o Nazareno, fosse formado por sua maioria de homens - os doze apóstolos, por exemplo -, entretanto, não se pode negar a relevância das mulheres no período terreno de sua vida. A princípio pela sua própria encarnação, uma vez que Jesus, considerado como Cristo, embora sendo

\footnotetext{
${ }^{2}$ Todas as datas deste artigo são da Era Comum (E.C.), salvo quando expresso em contrário.

${ }^{3}$ Concordamos com André Leonardo Chevitarese $(2011,9)$ que defendeu a proposição de que as experiências religiosas são sempre plurais, e, consequentemente, não existem apenas Cristianismo, Judaísmo, Islamismo etc no singular. Então, temos Cristianismos, Judaísmos, Islamismos etc no plural. Por isso, usamos nesse parágrafo a palavra Cristianismos, para expressar a pluralidade das experiências religiosas dentro da religião cristã. Então, usaremos em todo artigo as expressões Cristianismo ou religião cristã, para exprimir a experiência religiosa cristã católica - salvo aquelas diferentes, que serão enunciadas.
} 
AS MATRONAS DA IGREJA DE ROMA NA ANTIGUIDADE TARDIA

Fabiano de Souza Coelho

uma divindade para seus seguidores, nasceu de forma comum do ventre de uma mulher. Igualmente, temos nos relatos dos livros dos Evangelhos a figura feminina nos momentos em que Jesus realizava seu ensino religioso, a comensalidade, as curas, na hora de sua crucificação, morte, sepultamento e, por fim, um grupo de mulheres, lideradas por Maria Madalena, foram as primeiras que testemunharam a Ressurreição ${ }^{4}$ (SALISBURY, 2002, 45; SILVA, 2006, 308).

Dentro do ambiente judaico, a figura de Jesus de Nazaré, descrita nos Evangelhos, foi-nos apresentada como aquele que acolhia e defendia a dignidade da mulher. Nesses textos religiosos, percebemos que o Nazareno permitia ser acompanhado por mulheres, procedendo de uma maneira diferente dos rabinos judeus tradicionais, pois admitia que elas fossem suas discípulas. Jesus não se sujeitou às convenções sociais de seu tempo a respeito de mulheres de má reputação, incluindo a figura feminina em seu grupo. Além do mais, o Nazareno não reservava seus ensinamentos apenas para os homens (ALONSO DÍAZ, 1975, 1819; FABRIS; GOZZINI, 1986, 9).

Compreendemos que a seita judaica de Jesus de Nazaré, com essa postura, não fez distinção de pessoas e nem separação de gênero, e, por conseguinte, percebe-se a existência de uma comunidade religiosa com equidade entre homens e mulheres.

De fato, o ser humano na Antiguidade, em pormenor o indivíduo dos primeiros séculos dos tempos cristãos, era eminentemente religioso, e o sistema de crença invadia todas as esferas de sua vida, de suas ideias e seus sentimentos (TEJA, 1999, 151). Desse modo, os discípulos e as discípulas de Jesus, ulteriormente, fundaram as primeiras comunidades e, consequentemente, surgiu o Cristianismo, com novas experiências religiosas plurais que se expandiram para muitas regiões do mundo romano Antigo.

Além disso, essa nova religião, no seu primórdio, não era considerada, em termos oficiais, pelo Império Romano, uma religio licita, e representou, desde cedo, uma superstitio para os romanos politeístas (CHEVITARESE, 2006, 166). Entrementes, mesmo assim, o Cristianismo se assentou em diversos espaços físicos, sociais e geográficos no Império Romano. Inserida a essa nova religião

\footnotetext{
${ }^{4}$ A descrição da aparição de Jesus de Nazaré às mulheres nos foi retratada nos Livros Sinóticos e no Quarto Evangelho, a saber: Mateus 28, 1-8; Marcos 16, 5-7; Lucas 24, 1-10; João 20, 1-18.
} 
AS MATRONAS DA IGREJA DE ROMA NA ANTIGUIDADE TARDIA

Fabiano de Souza Coelho

surgiu a Igreja - ekklesia -, que a princípio abrangia uma esfera pequena, doméstica e privada, e posteriormente se tornou pública, notável e visível no Mundo Antigo. Então, como já sabemos, no decorrer do quarto século, essa Instituição se associou às estruturas do poder político temporal no Império Romano e, dessa maneira, conquistou destaque e predileção nessa sociedade.

No mundo grego, ekklesia era a assembleia política do povo (FLORISTÁN SAMANES, 1999, 354). Da mesma forma, pode ser entendido o vocábulo ekklesia como a "[...] reunião presente e em ato do povo, assembleia dos cidadãos livres numa cidade, reunidos para decidir assuntos que afetam seu próprio bem-estar" (FIORENZA, 1992, 385). Destarte, na perspectiva da história social, pode-se considerar ekklesia como um conjunto institucional capaz de organizar em torno de um sistema de crenças uma comunidade hierarquizada de fiéis, procedendo à padronização de um conjunto de sinais e rituais (GEREMEK, 1987, 167-169).

Por sua vez, a ekklesia sempre foi um espaço de inclusão e de exclusão de pessoas, ou seja, aqueles que creem e outros que não se adequavam à realidade proposta pelas autoridades e liderança cristãs. Assim posto, compreendemos que as experiências cristãs igualmente foram movimentos religiosos que, em seus primórdios, agregou pessoas tidas como marginalizadas na sociedade, inclusive as mulheres.

Não obstante, os autores dos primeiros textos cristãos não estavam interessados em nos mostrar a participação ativa das mulheres e igualmente dos marginalizados nos movimentos cristãos. Por conseguinte, as primeiras fontes dos Cristianismos transmitem muito pouco da realidade do grupo que era tido como aquele excluído de uma sociedade patriarcal (FIORENZA, 1992, 79).

Desse modo, a imagem da mulher no começo as comunidades cristãs oscilava entre estes dois pontos: condenação e exaltação (ALEXANDRE, 1993, 512). O lado negativo legado às mulheres cristãs foi marcado pelos escritos atribuídos a Paulo de Tarso $^{5}$, considerado apóstolo nessa nova religião. Ele

\footnotetext{
${ }^{5}$ Ao realizarmos a análise dos textos atribuídos a Paulo e estudar uma bibliografia especializada, constatamos a existência de alguns Paulos, nos discursos bíblicos considerados paulinos. Pois quando se efetua a leitura das cartas atribuídas a Paulo, estamos lendo passagens escritas por outras pessoas. Assim, nessa perspectiva, o Paulo histórico, apresentado nos textos neotestamentários, transforma-se em discursos pós-paulinos, pseudo-paulinos e, algumas vezes, antipaulinos, pois se observa nas epístolas de Paulo um personagem radical, um conservador e/ou até reacionário e contraditório (BORG; CROSSAN, 2009, p. 30-48).
} 
implantou um Cristianismo diferente e aberto para outras culturas não judaicas, especialmente os politeístas.

Em alguns trechos das cartas atribuídas a Paulo, tidas como Pastorais, observa-se a marginalização das mulheres nas comunidades cristãs, propondo uma visão androcêntrica de mundo. De acordo com Rinaldo Fabris e Vilma Gozzini $(1986,53)$, existe uma literatura antipaulina e feminista, a qual atribuiu o estigma de misógino a Paulo, que colocou as mulheres numa estrutura inferior na comunidade religiosa. Esse argumento tem como bases os textos que fazem a alusão ao uso do véu imposto às mulheres e outro em que se deve observar o silêncio nas assembleias cristãs ${ }^{6}$.

Esses textos paulinos foram utilizados pelos homens do Cristianismo católico como discurso de autoridade e retórica, particularmente pelos Padres da Igreja, para construírem justificativas e argumentos para alocarem a figura feminina numa esfera insignificante, subalterna, secundária, subordinada, coadjuvante, e até associada ao desvio religioso.

O trabalho e o protagonismo das mulheres na congregação cristã Antiga foram associados ao campo da heterodoxia para muitos autores da Patrística. Por exemplo, o escritor cristão, Tertuliano, desaprovou a liderança feminina, pois poderia ser instrumento de desvio dos homens.

Em contrapartida, ao se afastar dessa visão elencada acima, compreendemos que foram notórias as ações femininas na origem dos Cristianismos. Elas eram muito importantes para a manutenção material das comunidades religiosas e, por isso, as mulheres exerciam uma considerável influência. Assim, as primeiras comunidades cristãs eram dependentes das pessoas ricas, uma vez que essas financiavam suas amplas atividades de caridade e de trabalhos (CLARK, 2004, 174; FIORENZA, 1994, 332).

Desde o surgimento dos Cristianismos, temos registro de fontes que relataram as atividades de mulheres que atuavam entre os discípulos das comunidades e os líderes carismáticos itinerantes (GÖSSMANN, 1996, 34). Dessa maneira, também nos textos cristãos antigos, muitas mulheres foram lembradas por suas influências exercidas no âmbito dos serviços da formação religiosa, missão e

\footnotetext{
${ }^{6}$ Sobre o uso do véu nas comunidades, vide I Coríntios 11, 1-16. A respeito do silêncio das mulheres na comunidade, vide I Coríntios 14, 34-35 e I Timóteo 2, 11-12.
} 
AS MATRONAS DA IGREJA DE ROMA NA ANTIGUIDADE TARDIA

Fabiano de Souza Coelho

comunhão fraterna com os membros da comunidade eclesial (FABRIS; GOZZINI, 1986, 52).

Podemos destacar aqui algumas figuras e líderes cristãs, elencadas nos textos neotestamentários, a conhecer: Febe, Júnia e Prisca ou Priscila. Especialmente, Júnia foi considerada apóstola na comunidade romana, conforme testemunho pauliano à congregação de Roma. Desse modo, a ela se atribui um grau superior nas estruturas comunitárias cristãs, instituído diretamente por Jesus de Nazaré (SIRAGO, 1983, 100). Além do mais, ainda podemos salientar que na literatura, considerada pela Igreja Católica não canônica, "[...] os Atos Apócrifos as mulheres tinham um status de heroínas da sociedade" (CLARK, 1983, 21).

Numa perspectiva tida como heterodoxia, por aqueles grupos cristãos que se autoproclamavam ortodoxos, vários grupos gnósticos tinham permitido que as mulheres ensinassem publicamente e, no segundo século, o movimento carismático Montanista tinha célebres profetisas e dirigentes, como Priscila e Maximila. Além dessas duas personagens, temos uma terceira seguidora de Montano que se chamava Quintilla (CLARK, 1983, 160; HIDALGO DE LA VEGA, 2006, 58). Em resumo, o Montanismo dava ênfase à atividade religiosa e profética protagonizada pelas mulheres.

A presença dessas duas mulheres nos foi comprovada nos escritos de Eusébio de Cesareia. Assim, em sua obra Historia Ecclesiastica, descreve-nos de maneira pejorativa e deteriorada o movimento Montanista e as profetisas dessa experiência religiosa, nestes termos:

[...] o inimigo da Igreja de Deus, em grau máximo adversário do bem e amigo do mal, que jamais omitiu qualquer espécie de maquinação contra os homens, operava para ainda produzir heresias alheias contra a Igreja. Alguns dentre esses hereges, à maneira de serpentes venenosas, insinuavam-se na Ásia e na Frígia, exaltando Montano, como se fosse o Paráclito, e duas companheiras suas, Priscila e Maximila, supostas profetisas de Montano [...] (História Eclesiástica V, 14).

$\mathrm{Na}$ realidade, desde o tempo dos apóstolos, muitas mulheres cristãs que eram profetizas desenvolveram uma atuação muito eficaz na comunidade cristã no processo de propagação da nova religião e nas conversões de mulheres politeístas. 


\section{HISTORIA \\ AS MATRONAS DA IGREJA DE ROMA NA ANTIGUIDADE TARDIA \\ Fabiano de Souza Coelho}

Tal carisma conferia a essas mulheres uma autoridade significativa para aqueles e aquelas que as ouviam (HIDALGO DE LA VEGA, 1993, 238).

Nos primeiros séculos, as mulheres exerciam a liderança nos Cristianismos, especialmente de quatro maneiras: primeiro como patronas das congregações religiosas e proprietárias de congregações cristãs domésticas; segundo, associadas à ordem das viúvas - ordo viduarum - que serviam à comunidade cristã na caridade e de outras formas; terceiro, na qualidade de profetisas que falavam em outras línguas - glossolalia ${ }^{7}$ - e manifestavam outros dons espirituais; e, quinto, ao exercerem o ministério de diaconisas, ordenadas para realizarem determinadas celebrações litúrgicas eclesiais, especificamente para as mulheres (SALISBURY, 2002, 47).

A partir do século II, na comunidade cristã Oriental, foi institucionalizado o diaconato feminino, conforme o relato existente nas Constituições Apostólicas. Essa fonte cristã nos retrata a ordenação da diaconisa, nestes termos:

Eu, Bartolomeu, ordeno a propósito a diaconisa. O bispo impõe as mãos, estão presentes contigo o presbitério, os diáconos e as diaconisas, e diz: 'Deus eterno, Pai de Nosso Senhor Jesus Cristo, Criador do homem e da mulher, que enviastes o Espírito a Mirian, a Débora, a Ana, que não considerou uma indignidade que teu Filho unigênito nascera de uma mulher, que a Tenda do Testemunho e no Templo ordenastes guardiãs de tuas santas portas, agora também dirige seu olhar sobre essa serva admitida para o diaconato, dá-lhe o Espírito Santo, purifica-a de toda mancha da carne e do espírito, para que realize com dignidade a obra que lhe és confiada para tua glória e louvor de Cristo. Por meio Dele, a ti glória e adoração no Espírito Santo pelos séculos. Amém' (Constituciones Apostólicas XIX, 1-2, XX, $1-2)$.

As diaconisas cuidavam das mulheres enfermas e davam assistência para aquelas que iriam receber o batismo cristão. Ulteriormente, as diaconisas assumiram também a recepção das mulheres nas congregações cristãs durante as celebrações litúrgicas e eram intermediárias nos diálogos com os homens que tinham cargos no clero hierarquizado. Elas foram admitidas entre os membros do clero desde o século IV. As diaconisas eram ordenadas e delas se exigia o voto de continência perpétua.

\footnotetext{
${ }^{7}$ Glossolalia é conhecida como o falar em línguas. No âmbito da linguística, essa pode ser vista como uma espécie de pseudolinguagem. Numa perspectiva da sociedade, a glossolalia pode ser observada como um tipo verbal de comportamento - contudo não comunicável - que tem funções socioculturais em meio a vários grupos religiosos (GOODMAN, 1972, 15).
} 
Essas chamadas "diáconas" ou diaconisas exerciam funções de auxílio aos bispos nos trabalhos ligados à piedade cristã. Esse tipo de serviço ordenado no Oriente Romano foi o primeiro ofício religioso cristão no qual existia a obrigação da continência sexual, e, consequentemente, eram apenas admitidas como diaconisas as mulheres virgens ou viúvas casadas apenas uma vez (CLARK, 1983, 24; GÖSSMANN, 1996, 114-116).

Não obstante, no Ocidente do Império Romano, não existia de forma clara se a diaconisa recebia as ordens sagradas da mesma forma que os varões que tinham uma ocupação oficial na comunidade católica latina.

Assim, no terceiro século, relata-nos Hipólito de Roma sobre a ordenação feminina: "Ao ser instituída uma viúva, ela não deve ser ordenada [...]. A viúva será instituída somente por palavra e logo se reunirá com as outras. Não pode impor as mãos nela, pois não oferece oblação e nem tem serviços litúrgicos; a ordenação é para os clérigos [...]" (La Tradition Apostolique 10). Por conseguinte, esse tipo de ministério feminino ordenado no Cristianismo Antigo nunca foi aceito no Ocidente.

Os membros do clero cristão defenderam suas posições privilegiadas ante os leigos. Eles acolheram as mulheres como padroeiras e ofereciam a elas ofícios de colaboradoras do clero. Em torno do terceiro século, o papel das mulheres nas congregações cristãs era inconfundível. Dessa maneira, o fator crucial foi que essas mulheres foram incentivadas a permanecerem continentes e exortadas a se manterem viúvas depois da morte de seu primeiro esposo (BROWN, 1990, 128129).

Outrossim, desde os primeiros séculos de existência do Cristianismo, as mulheres comprometidas com essa religião realizaram uma atividade missionária tão ativa quanto a dos homens. $E$ até o quarto século, tivemos mulheres que foram singulares propagadoras da fé cristã. Ademais, elas participavam na fundação de comunidades religiosas, tinham cargos de dirigentes de agrupamentos cristãos domésticos e, provavelmente, as mulheres igualmente exerceram atividades como apóstolas ou discípulas (BUSSMANN, 1996, 313-314; RAMING, 1996, 434).

De fato, na experiência católica nos séculos II e III, observa-se um número significativo de mulheres que participavam nas comunidades cristãs. O gênero feminino ocupou um lugar central, tanto no âmbito missionário quanto no doutrinal, 
AS MATRONAS DA IGREJA DE ROMA NA ANTIGUIDADE TARDIA

Fabiano de Souza Coelho

sendo que a maioria dessas mulheres era da alta sociedade e tinham um significativo nível cultural (TEJA, 1986, 25-26).

Destarte, na cidade de Roma, até o terceiro século, as congregações cristãs eram organizadas dentro das residências de seus adeptos e, com isso, as mulheres tiveram um papel de destaque, influência, autoridade e de liderança religiosa nesse tipo de estrutura. Aquelas e aqueles que se ajuntavam nesse tipo de comunidade eclesial se faziam como um grupo igualitário (FIORENZA, 1992, 215-216; TORJESEN, 1993, 31-33).

Ademais, a religião cristã se tornou um credo muito atraente para um número significativo de mulheres de todos os grupos sociais romanos. Muitas delas foram seguidoras de Jesus de Nazaré e também existiram muitas que foram martirizadas. Todavia, as comunidades cristãs no seu início não buscaram uma mudança social radical. Assim, a administração eclesial e os rituais religiosos foram centralizados nas mãos dos homens, bem como o cuidado dos fiéis, no qual as mulheres estavam inseridas (FINLEY, 1990, 154).

A partir do terceiro século, os Cristianismos começaram a limitar a atuação das mulheres em suas comunidades. Quanto mais a experiência católica se hierarquizava em uma estrutura clerical, as mulheres foram restringidas das tarefas que outrora realizavam e, desta feita, foram sendo excluídas dos serviços e funções mais importantes no âmbito religioso, que eram realizados apenas pelos membros masculinos (BUSSMANN, 1996, 313-314; RAMING, 1996, 434; TEJA, 1986, 25-26).

No processo de estruturação dos agrupamentos cristãos nos primeiros séculos, as funções administrativas dos bispos, presbíteros e diáconos, paulatinamente, assumiram características ligadas à família patriarcal, e, com isso, os trabalhos e influências das mulheres foram sendo limitados para que não causar escândalos nessa sociedade que estava inserida numa cultura androcêntrica (FIORENZA, 1994, 335). Logo, observamos essa postura na seguinte instrução sobre o cargo do bispo cristão, desta maneira:

Fiel é esta palavra: se alguém aspira ao cargo de epíscopo, boa obra deseja. É preciso, porém, que o epíscopo seja irrepreensível, esposo de uma única mulher, sóbrio, cheio de bom senso, simples no vestir, hospitaleiro, competente no ensino, nem dado ao vinho, nem briguento, mas indulgente, pacífico, desinteresseiro. Que ele saiba governar bem a própria casa, mantendo os filhos na submissão, com toda a dignidade. Pois se alguém não sabe governar bem a própria 

convertido, a fim de que não se ensoberbeça e incorra na condenação que cabe ao diabo [...]. (1 Timóteo 3, 1-6, grifo nosso).

Assim, as relações existentes entre os homens e mulheres são relações sociais e não naturais, dado que essas foram construídas pela sociedade. Então, percebe-se que a divisão e assimetria de gênero foram estruturadas internamente pela comunidade católica, com decorrer dos primeiros séculos de Cristianismos, pois ela se assentou numa organização hierarquizada e sacerdotal, em torno de valores patriarcais, e a figura feminina, lentamente, foi perdendo espaço dentro desse organismo religioso e, consequentemente, ficou-se cristalizada a divisão de gênero nessa experiência cristã.

Diante disso, concordamos com Luise Schottroff (1996, 58-59), que nos demonstra que dentro da religião cristã o ofício masculino veio da organização do poder patriarcal do Império Romano Antigo e não das experiências comunitárias vivências pelos primeiros cristãos. Além disso, aprovamos a proposição defendida por Elisabeth Schüssler Fiorenza $(1988,127-286)$ que nos apresenta que uma religião assentada em uma hierarquia patriarcal masculina é contrária a uma comunidade de iguais.

Assim sendo, essa nova experiência religiosa no Império Romano, que na sua origem tendia à igualdade e paridade e a uma relação harmoniosa entre seus seguidores e suas seguidoras, ulteriormente privilegiou um arquétipo em detrimento do outro. Desse modo, não podemos nos furtar de pensar essas realidades numa perspectiva da categoria de gênero, pois essa está relacionada com que "[...] se refere a 'construções sociais', os papéis construídos para homens e mulheres na sociedade [...]" (SOIHET, 1997, 279).

Doravante, para a religião cristã patriarcalizada, a mulher ideal seria aquela esposa fiel e mãe generosa, inteiramente dedicada ao cuidado da casa. A família tinha como base as relações patriarcais, nas quais o homem era pai e patrono, e a mulher, como esposa, era convidada a se submeter ao seu cônjuge.

Toda essa conjuntura não estimulou os primeiros seguidores do Cristianismo a propor um novo modelo à condição das mulheres. Eles unicamente reproduziram a estrutura e organização familiar de sua época. Percebemos, então, tal posição nos discursos das cartas consideradas como Pastorais, deste modo: 
AS MATRONAS DA IGREJA DE ROMA NA ANTIGUIDADE TARDIA

Fabiano de Souza Coelho

[...] Quanto às mulheres, que elas tenham roupas decentes, se enfeitem com pudor e modéstia; nem tranças, nem objetos de ouro, pérolas ou vestuário suntuoso; mas que se ornem, ao contrário, com boas obras, como convém a mulheres que se professam piedosas. Assim, durante a instrução a mulher conserve o silêncio, com toda submissão. Não permito que a mulher ensine, ou domine o homem. Que conserve, pois, o silêncio. Porque primeiro foi formado Adão, depois Eva. E não foi Adão que foi seduzido, mas a mulher que, seduzida, caiu em transgressão. Entretanto, ela será salva pela sua maternidade, desde que, com modéstia, permaneça na fé, no amor e na santidade [...] (1 Timóteo 2, 9-15, grifo nosso).

Com isso, com o processo de expansão da experiência católica no mundo romano, cuja estrutura organizacional defendeu a sucessão dos clérigos formada por pessoas puramente do gênero masculino, adotou-se um discurso voltado para os homens e, consequentemente, as mulheres ficaram na esfera privada e individual. Destarte, os relacionamentos conjugais perfeitos eram aqueles em que o homem era casado com a Igreja, como bispo, sacerdote, diácono etc, e as mulheres com a divindade cristã, sendo virgens, viúvas consagradas e continentes (SIQUEIRA, 2004, 157). Sendo assim, muitas mulheres buscavam uma libertação nessa religião por meio da sublimação, uma ideia que era tida pelos cristãos, que estava além da purificação e pureza, castidade e continência (FINLEY, 1990, 154).

Colocado isso, a mulher se transformou em objeto de reflexão por parte do Cristianismo na Antiguidade Tardia. Dessa maneira, no século IV, os Padres da Igreja cristalizaram o ideal místico de mulher, com potencial oposto dos meios politeístas, o que contribuiu de forma prática com o desenvolvimento do monacato feminino (MARCOS SANCHEZ, 1987, 235-238).

Além disso, asseverou Elisabeth Schüssler Fiorenza $(1992,359)$ que:

[...] a patriarcalização gradual da Igreja e sua liderança [feminina] gerou também a "Igreja das mulheres", aquela reunião de mulheres não casadas e independentes que parecem ter formado sua própria Igreja doméstica e associação religiosa. Isso foi possível porque associações e cultos religiosos reservados às mulheres eram conhecidos no Mundo Antigo. Não obstante, o episcopado gradualmente patriarcalizado buscou, desde muito cedo, controlar social, legal e economicamente essas associações de mulheres [...].

$\mathrm{Na}$ comunidade cristã na cidade de Roma, na segunda metade do quarto século e no começo do quinto, tivemos figuras femininas da aristocracia que 
formaram alguns núcleos de "Igreja das Mulheres" no âmbito de suas residências, palácios e mansões. Essas mulheres tinham preferência pela vida ascética e monástica e a adesão a esses novos valores advindos do Cristianismo representou um caminho para exercerem suas aptidões e poder no meio social e religioso.

No decorrer de todo o século IV, o lar cristão e a congregação religiosa local continuaram a ser o espaço onde as mulheres buscavam a santidade, tal como foi para homens e mulheres nos primórdios dos Cristianismos. Contudo, ancorado sobre esse tipo de devoção que veio a ser elaborado o significado simbólico do estado virginal perpétuo (BROWN, 1990, 220).

A grande maioria dessas mulheres romanas advinha dos grupos sociais mais elevados da cidade de Roma. Desta feita, a comunidade católica dessa cidade contou com um número expressivo de mulheres que formaram grupos religiosos importantes e serviram de exemplo para os retóricos e polemistas cristãos escreverem sobre o testemunho de sua vida piedosa para todo Império Romano, como modelos de matronas cristãs e de vida perfeita.

As mulheres ricas do Império Romano, inserido no ideal religioso cristão, trabalhavam para a causa religiosa e administravam seu patrimônio e fortunas em prol do Cristianismo. Portanto, em Roma, a elite familiar proporcionou à Igreja Católica uma gama de recursos, no âmbito material, político e social. Desse modo, os bens materiais em abundância concediam grande autoridade e prestígio para a figura feminina (FIORENZA, 1992, 325; SESSA, 2012, 1-19).

$\mathrm{Na}$ sociedade romana na Antiguidade Tardia, mediante todas as pressões sociais, as mulheres ricas puderam escolher, em certa medida, seu próprio caminho. Muitas se tornaram cristãs devotas e patronas dos líderes religiosos cristãos. Um grupo significativo de mulheres causou uma reavaliação e negociação em torno dos papéis femininos. Essas personagens fizeram parte do intricado processo de cristalização da Igreja Católica a partir do quarto século (SIQUEIRA, 2012, 86).

Os séculos IV-V, de fato, foram períodos nos quais a figura feminina cristã pôde construir seus próprios modelos de piedade e serem mentoras de outras mulheres. Em resumo, elas seriam modelos de religiosas que poderiam ser imitadas por gerações futuras de mulheres. Assim, os Padres da Igreja teciam inúmeros elogios às mulheres cristãs ligadas à alta aristocracia romana que renunciavam suas 
AS MATRONAS DA IGREJA DE ROMA NA ANTIGUIDADE TARDIA

Fabiano de Souza Coelho

vidas luxuosas e de prestígio social, os laços familiares, para aderirem ao ascetismo (CLARK, 1983, 19-20).

Desse modo, portanto, reitera Marilyn Dunn (2008, 670), que o primeiro grupo de ascéticos no Ocidente Romano era formado em sua totalidade por mulheres. $\mathrm{Na}$ segunda metade do quarto século, os mais elevados integrantes dessa primeira geração foram figuras femininas aristocratas de Roma que adotaram a vida religiosa e de renúncias - as viúvas Marcela, Paula e Melânia, a velha.

Com a difusão da vida monástica para o Ocidente, depois de sua institucionalização no Oriente Romano nos séculos terceiro e quarto, essa experiência religiosa cristã foi caracterizada no mundo latino de forma individualizada no ambiente doméstico ou coletivamente, com a edificação de mosteiros para homens e mulheres. Destarte, um número significativo de mulheres da alta aristocracia romana escolheu o ascetismo como modo de vida. Tais mulheres renunciavam ao casamento, se elas fossem virgens; repudiavam um novo matrimônio, se elas fossem viúvas; e, ainda, as casadas se abstinham das relações conjugais (TORRES PRIETO, 2009, 50).

No começo do quarto século, famílias aristocráticas tradicionais de Roma tinham se convertido ao Cristianismo. Muitas mulheres desse grupo social foram as primeiras que aderiram a essa manifestação religiosa e influenciaram os demais membros de sua família.

Em Roma, ilustres mulheres dos altos estratos sociais, em geral, as viúvas e as virgens, entregaram-se a diversas renúncias, mesmo dentro do ambiente familiar e, assim, levavam uma vida consagrada à religião cristã. Esses modelos de religiosas se adaptaram ao novo ideal feminino predominante entre os círculos cristãos, com o aparecimento do monacato e o evergetismo praticado pelas mulheres.

As mulheres cristãs religiosas do Mundo Romano Antigo não viviam com seus familiares, nem desejavam ostentar seus ornamentos e riquezas. Elas buscavam uma renúncia contínua, a realização de obras de piedade e assistência aos mais necessitados da sociedade, por meio de um desprendimento perene e uma generosidade diferente de outros tempos (SIRAGO, 1993, 6).

Consideramos que tais figuras femininas romanas - matronas e patronas cristãs - foram de singular importância para aquele mundo na Antiguidade Tardia, 
AS MATRONAS DA IGREJA DE ROMA NA ANTIGUIDADE TARDIA

Fabiano de Souza Coelho

mesmo em meio a uma sociedade que privilegiava os homens. Destarte, na cidade de Roma, na região do Aventino, sobressaiu-se um grupo de mulheres conduzido pela matrona Marcela.

Marcela viveu da metade do século IV até aproximadamente o início do século $\mathrm{V}$, na cidade de Roma, e era da tradicional família dos Caeonii. Dessarte, após seis meses de casada, ficou viúva e recusou com vivacidade a proposta de um novo matrimônio com o cônsul Cereal, apesar das inúmeras recomendações de sua mãe, Albina (DUNN, 2008, 670; DI BERARDINO, 2002, 877-878).

Marcela teve contato com a experiência religiosa ascética e foi influenciada pela leitura da obra sobre a vida de Antônio e das experiências monásticas do vale do rio Nilo, relatadas pelos bispos Pedro de Alexandria e Atanásio quando estavam exilados na cidade de Roma. Desse modo, essa viúva consagrada foi uma das precursoras do monacato feminino na cidade de Roma. Viveu uma vida religiosa em sua mansão em Aventino, com sua mãe e outras nobres romanas (KELLY, 1975, 92; SALISBURY, 2002, 203-204).

Jerônimo de Estridão atestou essa assertiva sobre Marcela, com estas palavras:

\begin{abstract}
Nenhuma mulher nobre conhecia naquele tempo a profissão dos monges, nem essa novidade, atrevia-se a tomar aquele nome que se tinha então por ignominioso e estava desacreditado entre as pessoas. Por meio dos sacerdotes alexandrinos, Atanásio e Pedro que fugindo da perseguição ariana e refugiaram-se em Roma como um porto seguro de sua comunhão, Marcela conheceu a maneira de viver do bem-aventurado Antônio, que vivia naquela época, e os monastérios de Pacômio [...] (Carta 127, 5).
\end{abstract}

A residência de Marcela na região de Aventino veio a se transformar, de alguma maneira, em uma espécie de monastério para viúvas e virgens. Desta feita, essa experiência religiosa vivenciada pelas mulheres em Aventino foi uma forma primitiva de monaquismo feminino.

O círculo de Marcela era formado pelas seguintes mulheres: Albina, Paula, Eustóquia, Blesilla, Asela, Marcelina, Felicidade e Leia. Assim, a vida dessas religiosas era marcada pela modéstia e uso de roupas simples, fuga das relações sociais comuns, estudos bíblicos, visitas discretas às tumbas dos mártires e às basílicas romanas, renúncia do conforto e da vaidade pessoal, prolongados e 
AS MATRONAS DA IGREJA DE ROMA NA ANTIGUIDADE TARDIA

Fabiano de Souza Coelho

rigorosos jejuns e prática de todos os tipos de renúncia sexual (KELLY, 1975, 93). Além do mais, podemos testificar a presença de mais uma virgem nesse grupo, Princípia - a matrona Marcela, até o final de sua vida, foi mãe espiritual dessa virgem romana.

Em vista disso, dentro do grupo de mulheres em Aventino, tínhamos aquelas que praticavam um austero ascetismo e outras mais moderadas, uma vez que realizavam apenas renúncias mais equilibradas, orações comunitárias, estudos, e abdicavam dos luxos da sociedade romana.

Entre as frequentadoras desse círculo cristão feminino, também se evidenciou a matrona Paula. Ela era de uma abastada família da aristocracia romana, descendente dos Scipios - Cipião, general que defendeu Cartago. Seus genitores conseguiram um bom casamento para ela com o nobre romano, Júlio Toxocio descendente da família de Julios Caesar. Paula teve cinco filhos, dos quais quatro eram mulheres e um homem. Posteriormente ao nascimento de seu último filho, Paula fez voto de continência com seu esposo e aderiu às práticas religiosas cristãs. Com a morte de seu marido, mesmo sendo bem jovem, encontrou conforto na religião. Assim sendo, Paula ajudou com sua fortuna os pobres e os doentes da cidade de Roma (SALISBURY, 2002, 263-264).

Paula, ao se tornar viúva, dedicou-se à vida ascética e aos estudos bíblicos junto ao grupo de Aventino. Essa viúva romana era mais nova que Marcela, todavia, junto com ela exerceu a liderança nesse círculo cristão feminino ou nessa Igreja de Mulheres no período em que esteve em Roma ${ }^{8}$.

Outra mulher desse agrupamento religioso era Julia Eustóquia. Uma nobre nascida em Roma, filha da viúva Paula, irmã de Blesilla e de Paulina, e cunhada do senador Pamáquio. Eustóquia viveu entre os finais do século quarto e início do quinto século (DI BERARDINO, 2002, 544).

Eustóquia era uma mulher piedosa que adotou com convicção os ideais ascéticos, consagrou sua virgindade ao Cristianismo e colocou-se o serviço da congregação religiosa cristã (KELLY, 1975, 100-101). Dessa maneira, a família de

\footnotetext{
${ }^{8}$ No ano 385, Paula, em companhia de suas servas e de sua filha, Eustóquia, seguiu Jerônimo até a Palestina, e depois de conhecer os monges do deserto de Nítria, assentou-se na cidade de Belém, em 386. Nessa cidade, ajudou a fundar um mosteiro masculino e um feminino e uma hospedaria para os peregrinos (DI BERARDINO, 2002, 1106).
} 
AS MATRONAS DA IGREJA DE ROMA NA ANTIGUIDADE TARDIA

Fabiano de Souza Coelho

Eustóquia a formou dentro dos ideais ascéticos cristãos e ela permaneceu nesse estado de renúncia sexual por toda a sua vida.

Ainda no que concerne às mulheres pertencentes ao grupo de Aventino, a jovem viúva Blesilla, em determinado tempo de sua vida, assumiu o rigorismo ascético. Ela era filha mais velha de Paula. Na juventude, Blesilla era muito bela, talentosa e amava a vida alegre da aristocracia romana. Ela aproveitou intensamente os prazeres que eram oferecidos pela cidade de Roma - jantares, festas, teatros, jogos, termas e a companhia de outros jovens. Na faixa dos dezoito anos, ela se casou, todavia, em poucos meses, tornou-se viúva e herdou a fortuna de seu esposo.

Por ainda ser muito jovem, Blesilla gastou tempo e parte de sua riqueza com roupas e sua aparência, mas, sua mãe Paula e a irmã Eustóquia a advertiram sobre os excessos que cometia. Depois de ficar doente e ter recobrado a saúde, Blesilla mudou de postura, aproximou-se das práticas ascéticas de Aventino, dos estudos dos textos bíblicos, das línguas grega e hebraica (SALISBURY, 2002, 32-33).

No entanto, Mar Marcos Sanchez $(1990,506)$ afirma que Jerônimo, perante a adesão à vida ascética da jovem viúva, Blesilla, propôs a ela severos jejuns até sua desnutrição, como um instrumento de expiação dos seus pecados, cometidos outrora. Enfim, a filha da matrona Paula veio a falecer após quatro meses de renúncias ascéticas rígidas - pouco depois de iniciar tais práticas de renúncias ${ }^{9}$.

Além do mais, certificamos que parte significativa da casa da viúva Paula integrou o círculo de Marcela, naquela época. A matrona Paula foi protagonista da difusão dos valores monásticos cristãos para membros de sua família, estirpe considerada um grupo da elite romana.

Por sua vez, Albina era mãe de Marcela e uma viúva continente. A posição social de sua família aristocrática já foi retratada anteriormente - essa senhora era descente dos Ceionii Ruffi. Dessa forma, essa matrona, motivada pelos valores

\footnotetext{
9 Jerônimo, em 384, foi acusado por muitos da morte dessa jovem promissora, pois o monge de Estridão a aconselhou a realizar inúmeras mortificações corporais, jejuns etc. Desse modo, o falecimento de Blesilla polarizou a opinião sobre Jerônimo na cidade de Roma, por causa dos convites à conduta de um ascetismo extremo (SALISBURY, 2002, 33). Todavia, Jerônimo consolou Paula redigindo uma carta $-\mathrm{n}^{\circ} 39$ - e fez uso deste discurso: "[...] eu dou minha palavra, prometo e comprometo-me a que minha língua sempre proclamará o seu nome, dedicarei meus trabalhos a ela, [...]. Não existirá nenhum plano de meus escritos em que não soe Blesilla. Aonde queira chegar os rastros de minha palavra, ali, com meus esforços irá a peregrina Blesilla [...]' (Carta 39, 8).
} 
AS MATRONAS DA IGREJA DE ROMA NA ANTIGUIDADE TARDIA

Fabiano de Souza Coelho

ascéticos existentes na sociedade romana, na Antiguidade Tardia, dedicou-se à vida religiosa e de renúncia ao lado de sua filha em Aventino.

Outrossim, a religiosa Asela, irmã de Marcela, foi influenciada por seus familiares a ter uma vida piedosa. Os genitores de Asela a consagraram como uma mulher virgem antes mesmo de seu nascimento e, com dez anos, exteriorizaram esse voto religioso. Naquele tempo, por ainda não existirem conventos na cidade de Roma, Asela viveu como religiosa nas dependências de sua residência.

Por muitas vezes evitava a companhia de sua irmã mais velha, no momento em que Marcela estava a caminho de contrair matrimônio. Asela viveu uma vida austera e ascética, falava muito pouco, particularmente mal se comunicava com os homens. Assim, ela era uma pessoa discreta, jejuava e praticava duras penitências. Posteriormente, quando sua irmã Marcela criou o círculo de encontro para mulheres religiosas em Aventino, a virgem Asela se ajuntou a esse grupo e se transformou mais tarde em uma liderança nesse meio feminino (SALISBURY, 2002, 22).

Por fim, podemos assinalar mais uma religiosa desse grupo cristão da qual temos registro: a matrona Leia, amiga de Marcela. Era adepta do ascetismo, participava do grupo de Aventino, vivia isolada num pequeno quarto, fazia várias renúncias ascéticas extremas e praticava constantes jejuns. Logo, a matrona Leia motivava outras damas e senhoras da cidade de Roma a seguir seu exemplo de consagrada à religião cristã (SALISBURY, 2002, 204; SIRAGO, 1993, 31).

Posto tudo isso, conseguimos asseverar que as mulheres do círculo de Aventino foram tanto romanas como cristãs, pois essas, por fazerem parte das famílias aristocráticas, foram educadas culturalmente na tradição clássica. Mesclando a literatura e filosofia tradicional com os elementos cristãos, essas mulheres religiosas ricas, de forma muito sistematizada, aprofundaram-se nos estudos das Escrituras (GONNZÁLEZ SALINERO, 2011, 557).

Em suma, a experiência ascética vivencia por viduae romanas da elite senatorial - Marcela e Paula - proporcionou que as crenças cristãs ingressassem no ambiente aristocrático da nobilitas da cidade de Roma (MATTIOLI, 1990, 237).

Além dessa comunidade religiosa cristã em Aventino, na Igreja de Roma, tivemos outras figuras femininas que se dedicaram à vida piedosa e a busca pela perfeição. Muitas mulheres servas e escravas dessas matronas ricas acompanhavam suas senhoras e, consequentemente, podemos inclusive deduzir, 
de forma genérica, que tais fossem adeptas de práticas cristãs em derredor do ascetismo. Não obstante, Elizabeth A. Clark $(1983,204)$ explicita que não se pode afirmar que as mulheres da aristocracia romana representavam as outras mulheres pertencentes a grupos sociais mais baixos no mundo romano na Antiguidade Tardia.

Podemos, também, salientar que a mãe de Dâmaso, bispo de Roma, pertencia à ordem das viúvas, e uma de suas irmãs, Irene, tinha consagrado a sua virgindade ao serviço da religião cristã (DI BERARDINO, 2002, 376). Assim, no decorrer da segunda metade do quarto século, essas mulheres exerciam atividades religiosas para comunidades cristãs dessa cidade.

Mais uma religiosa, nesse período, era Fúria, viúva e matrona romana, membro da aristocracia da cidade e defensora da considerada virtude continente para as mulheres como viúvas. Ela era cunhada de Blesilla e sua família era descendente de Furius Camillus, considerado salvador de Roma e, também, dos Gracos (KELLY, 1975, 191; SERRATO GARRIDO, 1993, 82; SIRAGO, 1993, 37).

Da mesma maneira, tínhamos a matrona Fabíola, que fundou um hospital em Roma e serviu em um abrigo para pobres em Óstia (cidade antiga na costa do mar Tirreno) e, por essa razão, ficou famosa por sua generosidade e caridade.

Fabíola era uma matrona rica pertencente à alta aristocracia da cidade de Roma, que tinha se divorciado de seu marido adúltero - ele gostava de se deleitar nos prazeres lascivos - e que contraiu novas núpcias ainda em vida de seu primeiro esposo. Depois da morte de seu companheiro, como forma de se redimir de suas faltas, fez penitência pública, abraçou uma vida austera ascética e colocou sua considerável fortuna à disposição de trabalhos caritativos cristãos (CLARK, 1983, 181-182; DI BERARDINO, 2002, 562).

Além do mais, Fabíola realizou visita a terras do Oriente do Império Romano, nas regiões consideradas sagradas para os cristãos, ou seja, ela também foi uma matrona cristã peregrina que conheceu especialmente as cidades de Belém e Jerusalém, antes do ano 395 (SERRATO GARRIDO, 1999, 348).

Faltônia Proba também era uma matrona influente na cidade de Roma - gens Anicii. Ela estava ligada à alta aristocracia romana e foi filha, esposa e mãe de cônsules romanos. Proba teve três filhos, dentre os quais dois deles se chamavam Anicius Hermogenianus Olybrius - cônsul em 379 e prefeito de Roma em 391 - e Anicius Probinus, que serviram o Império no ano 395. Olíbrio se casou com Juliana, 
que também fazia parte de uma importante família nobre de Roma. Desse matrimônio, nasceu Demetríades, que foi consagrada como virgem ao Cristianismo. Desta feita, tanto Proba quanto Juliana, ao se tornarem viúvas, consagraram-se e fizeram votos religiosos (HUNTER, 2007, 81; SILVA; LIMA, 2010, 26; DI BERARDINO, 2002, 1186).

Além disso, a virgem Demetríades, neta de Proba, descendia da gens denominada Anícios, uma das primeiras famílias politicamente ilustres romanas que se converteram à religião cristã. Dessarte, depois do falecimento de seu pai, junto com sua mãe, Anícia Juliana assentou-se na cidade de Cartago, em 410, após o Saque de Roma.

Assim posto, Demetríades renunciou à vida matrimonial para ser uma religiosa consagrada e recebeu a imposição do véu pelas mãos do bispo Aurélio, da cidade de Cartago. E, posteriormente, ao regressar à cidade de Roma, a virgem Demetríades financiou a construção de uma Igreja dedicada a Santo Estevão na região da Via Latina (CLARK, 1983, 231; HUNTER, 2007, 81; DI BERARDINO, 2002, 387).

No século IV, significativas famílias ricas romanas se transformaram em cristãs. Com essa postura, muitas mulheres pertencentes a essas famílias vivenciavam uma piedade religiosa de uma forma que as diferenciava das demais mulheres contemporâneas. Algumas entendiam que uma maneira de seguir a religião cristã era renunciar os familiares, a sociedade e as riquezas que marcavam suas vidas.

Concordamos com Elizabeth Clark $(1983,156)$ que nos mostra que ascetismo foi uma via aberta para que algumas mulheres da Antiguidade cristã pudessem superar a condição social e cultural imposta para elas e que era vivenciada pela maioria das mulheres daquele tempo.

Além do mais, dentro das experiências cristãs, na Antiguidade Tardia, as mulheres ricas poderiam alcançar prestígio pela generosidade de doações à congregação religiosa e na realização do serviço consagrado à divindade - Deo Dicatae $^{10}$.

${ }^{10}$ Apontado por S. Elm (1994) e M. Serrato Garrido (1993) para se referir o feminino consagrado à divindade cristã. 


\section{HISTÓRIA}

AS MATRONAS DA IGREJA DE ROMA NA ANTIGUIDADE TARDIA

Fabiano de Souza Coelho

Finalmente, considerando toda essa conjuntura, poderíamos nos atrever em dizer e intitular todas essas mulheres consagradas cristãs, examinadas neste trabalho, como as Madres da Igreja (uma diferenciação do clássico e tendencioso termo Padres da Igreja), em rompimento com o histórico patriarcalismo cristão católico, propondo uma alternativa e o pensar em uma igualdade de gênero nessa experiência religiosa cristã.

\section{REFERÊNCIAS}

\section{Fontes}

Constituciones Apostólicas. Introducción, traducción y notas de Juan José Ayán Calvo. Madrid: Ciudad Nueva, 2010.

JERÓNIMO, S. Cartas de San Jerónimo. Vol. I. Edición bilingüe introducción, versión y notas por Daniel Ruiz Bueno. Madrid: Biblioteca de Autores Cristianos, 1963.

JERÓNIMO, S. Epistolario. Vol. II. Edición bilingüe traducción, introducciones y notas por Juan Bautista Valero. Madrid: Biblioteca de Autores Cristianos, 1993.

EUSÉBIO DE CESAREIA. História Eclesiástica. Traduzido pelas Monjas Beneditinas. São Paulo: Paulus 2000.

HIPPOLYTE DE ROME. La Tradition Apostolique. Introducion, Traducion et notes Bernard Botte. Paris: Les Éditions du Cerf, 1984.

\section{OBRAS DE REFERÊNCIA}

ALEXANDRE, M. Do anúncio do Reino à Igreja: papéis, ministérios, poderes femininos. In: DUBY, G., PERROT, M. (Orgs.). História das Mulheres no Ocidente. v. 1: A Antiguidade. Porto: Afrontamento, 1993, p. 511-563.

ALONSO DÍAZ, J. Inauguración de Curso Canto Blanco (Madrid): Proceso de dignificación de la mujer a traves de la Biblia. Madrid: Gráficas Reunidas, 1975.

BORG, M. J.; CROSSAN, J. D. The First Paul: Reclaiming the Radical Visionary Behind the Church's Conservative Icon. New York: HarperCollins, 2009.

BROWN, P. Corpo e sociedade: o homem, a mulher e renúncia sexual no início do cristianismo. Rio de Janeiro: Jorge Zahar, 1990. 


\section{HISTÓRIA}

AS MATRONAS DA IGREJA DE ROMA NA ANTIGUIDADE TARDIA

Fabiano de Souza Coelho

CHEVITARESE, A. L. Cristianismo e Império Romano. In: SILVA, G. V.; MENDES, N. M. (Org). Repensando o Império Romano. Rio de Janeiro: Mauad/Edufes, 2006, p. 161-173.

Klinê, 2011.

Cristianismos: questões e debates metodológicos. Rio de Janeiro:

CLARK, E. A. History, Theory, Text: historians and the linguistic turn. Cambridge and London, Harvard University, 2004.

A. Ideology, History, and the Construction of "Woman" in Late Ancient Christianity. Journal of Early Christian Studies, Baltimore/London, vol. 2: 2, p. 155184, 1994.

Women in the Early Church. Wilmington: Michel Glazier, 1983.

DI BERARDINO, A. (Org). Dicionário Patrístico e de Antiguidades cristãs. Petrópolis: Vozes, 2002.

DUBY, G., PERROT, M. (orgs.). História das Mulheres no Ocidente. v. 1: Antiguidade. Porto: Afrontamento, 1993.

DUNN, M. Asceticism and monasticism, II: Western. In: CASSIDAY, A.; NORRIS, F. W. (Org.). The Cambridge History of Christianity: Constantine to c. 600 . Nova York: Cambrigde University, 2008, p. 669-690.

ELM, S. Virgins of God: The Making of Asceticism in Late Antiquity. Oxford: Clarendon, 1994.

FABRIS, R.; GOZZINI, V. A mulher na Igreja Primitiva. São Paulo: Paulinas, 1986. FEITOSA, L. C. Gênero e Sexualidade no Mundo Romano: a Antiguidade em nossos dias, História: Questões \& Debates, Curitiba, n. 48/49, p. 119-135, 2008.

FINLEY, M. I. As mulheres silenciosas de Roma. In: FINLEY, M. I. Aspectos da Antiguidade: descoberta e controvérsias. Lisboa: Edições 70, 1990, p. 143-156.

FIORENZA, E. S. As origens cristãs a partir da mulher: uma nova hermenêutica. São Paulo: Paulinas, 1992.

FIORENZA, E. S. In Memory of Her: a Feminist Theological Reconstruction of Christian Origins. New York: Crossroads, 1988.

Mujer y ministerio em El cristianismo primitivo. Selecciones de Teologia, São Paulo, nº 132, vol 32. Out/dez, 1994, p. 327-337.

FLORISTÁN SAMANES, C.; TAMAYOACOSTA, J-J. (Dir.). Dicionário de Conceitos Fundamentais do Cristianismo. São Paulo: Paulus, 1999. 


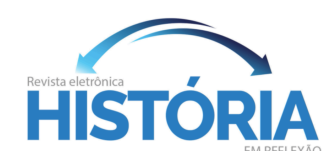

AS MATRONAS DA IGREJA DE ROMA NA ANTIGUIDADE TARDIA

Fabiano de Souza Coelho

GEREMEK, B. Igreja. In: ROMANO, R. (Dir.). Enciclopédia Einaudi, v. 12. Lisboa: Imprensa Nacional - Casa da Moeda, 1987, p. 161-214.

GONNZÁLEZ SALINERO, R. Ocio y ascesis aristocrática: Jerónimo y su lectio divina en Roma (382-385). Espacio, Tiempo y Forma, Madrid, Serie II, Historia Antigua, t. 24, 2011, p. 543-562.

GOODMAN, F. D. Speaking in Tongues: a Cross-cultural Study of Glossolalia. Chicago: University of Chicago Press. 1972.

GÖSSMANN, E. et. al. (org.). Dicionário de teologia feminista. Petrópolis: Vozes, 1996.

HIDALGO DE LA VEGA, M. J. Mujeres, carisma y castidad en el cristianismo primitivo. Gerión, Madrid, 11, 1993, p. 229-244.

M. J. Mujeres y carisma profético en el cristianismo primitivo: Las Profetisas Montañistas. Studia Historica - Historia Antigua, Salamanca, n. 24, 2006, p. 51-61.

HUNTER, D. G. Marriage, Celibacy, and Heresy in Ancient Christianity: The Jovinianist Controversy. New York: Oxford, 2007.

KELLY, J. N. D. Jerome: His Life, Writings, and Controversies. London: Duckworth, 1975.

MARA, M. G. Le funzioni della donna nella Chiesa antica. Rivista di pastorale liturgica, Firenze, 19/2, 1981, p. 5-16.

MARCOS SANCHEZ, M. M. La vision de la mujer en San Jerónimo a traves de su correspondência. In: La mujer en el mundo antiguo. Actas de las $\mathrm{V}$ Jornadas de investigacion interdisciplinaria. Madrid: Ediciones de la Universidad Autónoma de Madrid, 1986, p. 315-321.

MATTIOLI, U. La donna nel pensiero patristico. In: RICCHIUTO, M. A. Atti del Convegno Nazionale di Studi su La Donna Nel Mondo Antico. Torino: A.I.C.C. 1990, p. 223-242.

MORENO, F. San Jerónimo: la espiritualidade del desierto. Madrid: BAC, 1986.

PERROT, M. Minha história das mulheres. São Paulo: Contexto, 2013.

. Os silêncios do corpo da mulher. In. MATOS, M. I. S.; SOIHET, R. O Corpo feminino em debate. São Paulo: UNESP, 2003, p. 13-27.

RUBENSON, S. Asceticism and monasticism, I: Eastern. In: CASSIDAY, A.; NORRIS, F. W. (Org.). The Cambridge History of Christianity: Constantine to c. 600. Nova York: Cambrigde University, 2008, p. 637-668. 


\section{HISTÓRIA}

AS MATRONAS DA IGREJA DE ROMA NA ANTIGUIDADE TARDIA

Fabiano de Souza Coelho

SALISBURY, J. E. Encyclopedia of Women in the Ancient Word. Santa Barbara: ABCCLIO, 2001.

SERRATO GARRIDO, M. Ascetismo Femenino en Roma: Estudios sobre San Jerónimo y San Agustín. Cádiz: Universidad de Cadiz, 1993.

M. La experiencia ascética de las viudas de la aristocracia senatorial romana: más allá de la oración. Saitabi, València, 49, p. 341-359, 1999.

SESSA, K. The Formation of Papal Authority in Late Antique Italy: Roman Bishops and Domestic Shepere. Nova York: Cambrigde University, 2012.

SIRAGO, V. A. Cicadae noctium. Quando le donne furono monache e pellegrine. Soveria Manelli: Rubbettino, 1993.

Rubbettino, 1983.

V. A. Feminismo a Roma nel Primo Impero. Soveria Mannelli:

SILVA, G. V. A redefinição do papel feminino na Igreja primitiva: virgens, viúvas, diaconisas e monjas. In: SILVA, G. V.; NADER, M. B.; FRANCO, S. P. (Org). As Identidades no tempo: ensaios de gênero, etnia e religião. Vitória: EDUFES, 2006, p. 305-320.

SILVA, V. F.; LIMA, M. P. As cartas à Proba e à Juliana: relações de gênero nos escritos agostinianos. Revista Ártemis, João Pessoa, vol. 11, 2010, p. 21-34.

SIQUEIRA, S. M. A. A mulher na visão de Tertuliano, Jerônimo e Agostinho séc. II-V d. C. Tese de doutorado - Programa de Pós-graduação em História, Universidade Estadual Paulista, Assis, 2004.

SOIHET, R. História das Mulheres. In: CARDOSO, C.; VAINFAS, R. Domínios da História: ensaios de metodologia. Rio de Janeiro, Campus, 1997, p. 275-296.

TEJA, R. Emperadores, obispos, monjes y mujeres: protagonistas del cristianismo antiguo. Madrid: Trotta, 1999.

. La mujer en el mundo antiguo: sisteses historica y balance de la investigación reciente. In: La mujer en el mundo antiguo. Actas de las $V$ Jornadas de investigación interdisciplinaria. Madrid: Ediciones de la Universidad Autónoma de Madrid, 1986, p. 15-28.

TEPEDINO, A. M. As discípulas de Jesus. Petrópolis: Vozes, 1990.

TORJESEN, K. J. When women were priests: women's leadership in the early church and the scandal of their subordination in the rise of Christianity. San Francisco: Harper Collins, 1993. 


\section{HISTÓRIA}

AS MATRONAS DA IGREJA DE ROMA NA ANTIGUIDADE TARDIA

Fabiano de Souza Coelho

TORRES PRIETO, J. M. A Historia de un monje hereje: Joviniano y el conflicto entre matrimonio y virgindade en el siglo IV. In: MAR MARCOS, M. (Ed.). Herejes en la Historia. Madrid: Trotta, 2009, p. 49-75.

Artigo recebido em 02/04/2018

Artigo aceito em 18/06/2018 